\title{
Effect of Pole-Assisted Walking on Intramuscular Lipids in Elderly Nursing Home Residents
}

\section{Yoshinao Nakagawa ${ }^{1^{*}}$ and Masaaki Hattori ${ }^{2}$}

${ }^{1}$ Human Performance Lab; Otaru University, Japan

${ }^{2}$ Department of Community Development, Tokai University, Sapporo Campus, Hokkaido, Japan

*Corresponding author: Nakagawa Y, Human performancelab, Otaru University, 3-5-21, Midori, Otaru, Hokkaido, 047-8501, Japan, Tel/Fax: +81-134-27-5415; E-mail: nak@res.otaru-uc.ac.jp

Received date: July 13, 2017; Accepted date: July 24, 2017; Published date: July 31, 2017

Copyright: (C) 2017 Nakagawa Y, et al. This is an open-access article distributed under the terms of the Creative Commons Attribution License, which permits unrestricted use, distribution, and reproduction in any medium, provided the original author and source are credited

\begin{abstract}
The present study investigated the effects of a 10 week walking program using hiking poles on intra-and extramyocellular lipid (IMCL and EMCL) content in elderly as assessed by ${ }^{1} \mathrm{H}-\mathrm{MR}$ spectroscopy. Six nursing home residents aged between 65 and 84 years $(n=6)$ participated in the study. The subjects were asked to walk for at least 30 minutes a day, three days per week. Intramuscular and blood lipid concentrations were obtained at baseline and at after the 10 week study. ${ }^{1} \mathrm{H}-\mathrm{MR}$ spectra were acquired from the tibialis anterior (TA), soleus (SOL) and medial gastrocnemius (MG) muscles. Significant difference was not observed in IMCL concentrations on between before and after pole-assisted walking (PW) program (NS). A significant reduction was recognized in EMCL concentrations and EMCL/IMCL ratio on TA $(p<0.05)$ and MG $(p<0.01)$ between the values before PW and those after. Mean HDL$C(p<0.01)$ and TC $(p<0.05)$ concentrations increased after completion of the PW program. A decrease in VLDL-C $(p<0.05)$ and HDL-C/LDL-C ratio $(p<0.01)$ was also observed at this point. These results show that the PW program induces a decrease in intramuscular lipids and improves lipoprotein profiles in the elderly nursing home residents.
\end{abstract}

Keywords: Intra myocellular lipid; IMCL; EMCL; Pole; Nordic; ${ }^{1} \mathrm{H}$ MRS; Lipoprotein profiles

\section{Introduction}

The decline in human physical fitness that accompanies aging continues to attract attention concomitant with the rapid aging of many societies around the world. Mobility is indispensable for elderly people if they are to lead an independent life. The gradual weakening of muscle associated with the onset of age is of especial importance given its influence on walking ability in the old and frail. Strength-and endurance-training are used to maintain and enhance walking ability. Endurance training, which is the best kind of exercise for increasing/ maintaining mitochondrial concentration with aging, has generally resulted in relatively small functional benefits in nursing home patients [1]. In particular, it has been assumed that walking using poles, or some other form of support, encourages frail elderly people in their walking training by preventing falls. It is also believed to provide a remarkable aerobic effect.

In recent years, ${ }^{1} \mathrm{H}$-magnetic resonance spectroscopy $\left({ }^{1} \mathrm{H}\right.$-MRS) method has facilitated non-invasive measurement of intra-and extramyocellular lipids (IMCL and EMCL) in skeletal muscle. Fat is accumulated inside muscle fiber cells as IMCL, and outside muscle fiber cells as EMCL; and it is believed that the former exhibits a quicker turnover than the latter [2-4]. IMCL burns to produce energy directly into the mitochondria; and oxidation capacity differs according to the individual [5]. It is reported that obese and type 2 diabetic people have a low fat oxidation capacity in skeletal muscle, both at rest or in exercise [6-8]. It appears that this reduced fat oxidation capacity results in fat accumulation within muscle. Aerobic training enhances fat oxidation capacity in skeletal muscle [5]. It is known that an endurance athlete oxidizes more fat at rest or in exercise than a typical healthy person [9-12]. Therefore, aerobic activity may improve fat oxidation capacity in skeletal muscle and may affect accumulation of IMCL or EMCL. This study uses ${ }^{1} \mathrm{H}$-MRS method to elucidate the influence of pole-assisted walking (PW) program for a 10 week period on IMCL and EMCL levels in elderly nursing home residents.

\section{Methods}

Subjects (age: $75.6 \pm 6.7$ years) comprised six elderly people (one man, five women), all of whom had received approval from the Sapporo Medical University Ethics Committee.

They were chosen as subjects at a meeting at which the study program objectives were explained and all participated enthusiastically in the program. Their consent to be subjected to various kinds of monitoring was obtained prior to actual commencement of the PW program. All subjects resided in the same geriatric nursing home; and they were all provided with the same meals on any given day. The scope of exercise for relatively healthy elderly is limited. Moreover, it is necessary to take safety into consideration when prescribing such exercise. It is believed that $\mathrm{PW}$ prevents falls and provides safe exercise in frail elderly people as it realizes four-footed walking. The program used in this study consisted of endurance training in the form of poleassisted walking over a 10 weeks period. Each subject was assigned three or more sessions per week of PW for $30 \mathrm{~min}$ or more without exercise intervention. The intensity and time of the PW sessions were to be at a comfortable pace for each individual. They were instructed to record the number of steps $(7281 \pm 1311$ steps PW a day, mean \pm SD), walking duration (53.9 \pm 11.8 min a day, $4.3 \pm 1.8$ times a week) and body weight, every day for 10 weeks in a notebook supplied in advance. It was used a trekking pole (Kizaki Co., Ltd., Nagano, Japan, of a weight of $300 \mathrm{~g}$ with variable length). Before the PW program, each pole length was adjusted so that the elbow-joint angle made a 
ninety-degree angle. We provided instruction on proper use of the poles and walking technique.

The subjects were required to strip down to their underwear and to remove their socks in order to measure height and body weight. Body mass index (BMI; $\mathrm{kg} / \mathrm{m}^{2}$ ) was calculated at before (BEF) and after (AFT) the PW program. Body weight, lean body mass (LBM) and body fat percent ( $\%$ FAT) were measured by bioelectrical impedance using 8 tactile electrodes, in accordance with the manufacturer's instructions (In Body 3.0; Biospace, Seoul, Korea) [13]. In this study, physical characteristics before (BEF) and after (AFT) the PW program are listed in Table 1. Comparison of the data on values for BEF and AFT shows no significant differences in weight, BMI, LBM or \% FAT (N.S.).

\begin{tabular}{|c|c|c|c|c|c|c|}
\hline$(n=6)$ & Age (year) & Height (cm) & Body weight $(\mathrm{Kg})$ & BMI $\left(\mathbf{k g} / \mathrm{m}^{2}\right)$ & Body fat (\%) & LBM (kg) \\
\hline Before & $75.5 \pm 6.7$ & $150.01 \pm 0.1$ & $52.8 \pm 7.4$ & $23.4 \pm 3.2$ & $32.4 \pm 7.1$ & $35.4 \pm 7.9$ \\
\hline After & -- & -- & $52.6 \pm 7.2$ & $23.3 \pm 3.5$ & $31.9 \pm 6.6$ & $35.5 \pm 7.6$ \\
\hline
\end{tabular}

Table 1: Physical characteristics in before and after the PW program.

Blood samples were drawn between 17:30 and 18:00 p.m., at least 5 $\mathrm{h}$ after subjects had consumed identical meals, at BEF and AFT the PW program. These blood samples were analyzed for plasma lipids, lipoprotein cholesterol, $\mathrm{HbAlc}$ and glucose at the clinical test center in Sapporo. The serum was collected and stored at $4^{\circ} \mathrm{C}$ until analyzed. Total cholesterol (TC), triglyceride (TG), HDL-cholesterol (HDL-C), LDL-cholesterol (LDL-C) and VLDL-cholesterol (VLDL-C) for lipoprotein fractions were examined periodically during the course of treatment using Chol/Trig Combo, which identifies cholesterol and TG by differential staining [14]. Glucose and HbAlc were analyzed using enzymatic and high-pressure liquid chromatography (HPLC) methods. Each analysis was entrusted to the same clinical test center at both BEF and AFT.

Magnetic resonance images (MRI) for localization and ${ }^{1} \mathrm{H}$-MRS were acquired using a clinical $1.5 \mathrm{~T}$ whole body scanner system (Signa Horizon LX, GE Medical systems) at BEF and AFT the PW program. A standard head coil (28 cm diameter) was used for detection. In each examination, the subjects lay in a supine position with the right calf placed along the axis of the coil. Transverse T1-weighted MR images (TR, TE ms) were acquired to determine the placement of the ${ }^{1} \mathrm{H}$-MRS voxels, at a slice thickness of $5 \mathrm{~mm}, 28 \mathrm{~cm}$ field and $512 \times 512$ data matrix. The ${ }^{1} \mathrm{H}$-MRS was obtained from the tibialis anterior muscles (TA) at the maximum circumference of the calf. Voxel positions were placed so as to avoid vascular structures and gross adipose tissue deposits and ensure consistent orientation of muscle fiber along the magnetic field. As a consequence of this selection process and high spatial resolution, the lipid values determined in these studies represent a lower bound, particularly for EMCL. Localized proton spectra were obtained using a PRESS sequence with TE/TR=30/2000 ms and 128 averages with water suppression. Spectra were processed using the Nuts software package (Acorn NMR Inc. USA). Spectra were line broadened and phase and baseline corrected, and the resonances of interest were line fit at a mixed Lorentzian/Gaussian function. After correction for $\mathrm{T} 1$ and $\mathrm{T} 2$ relaxations, quantification of IMCL and EMCL content was carried out to compare intensity of $(\mathrm{CH} 2)_{n}$ (methylene) at $1.3 \mathrm{ppm}$ and $1.5 \mathrm{ppm}$ resonance to the water resonance intensity at $4.7 \mathrm{ppm}$ (Figure 1) [15-18]. The IMCL and EMCL values were corrected for multiple $\mathrm{CH}_{2}$ groups by using the methods described by Szczepaniak et al. [4]. The assumptions are as follows: 1) methlylene $\left(-\mathrm{CH}_{2}-\right)$ at $1.3 \mathrm{ppm}$ is a singlet (excluding $\mathrm{C} 2-\mathrm{C} 3$ methlylene, allylic, and diallylic methlylene), and 2) the mean IMCL structure is similar to trioleate [19]. IMCL and EMCL were quantified relative to muscle water by using units of $\mathrm{mmol} / \mathrm{kg}$ wet weight, assuming a tissue density of $1.05 \mathrm{~kg} / \mathrm{l}$ [4] and the number of $\left(\mathrm{CH}_{2}\right) \mathrm{n}$ groups per triglyceride chain for the average triglyceride molecule [20].

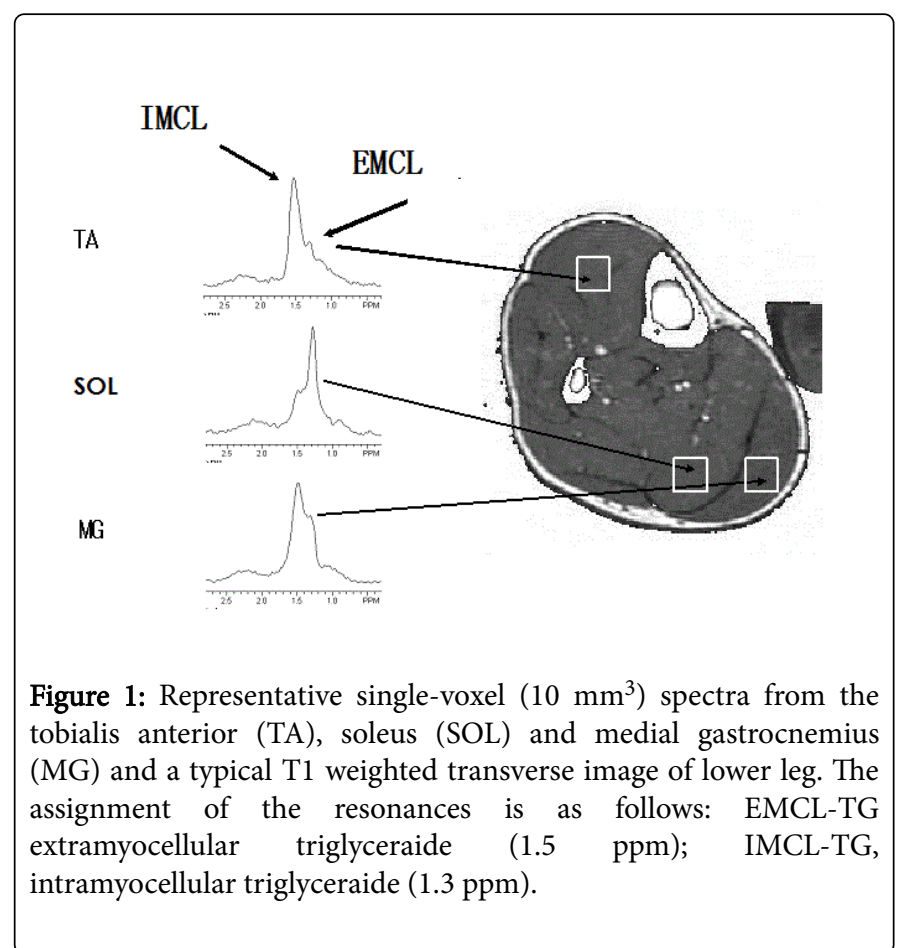

Results were shown as means \pm SD and $\mathrm{p}<0.05$ was considered to be the level of significance difference. Differences in the variables measured at before and after the PW program were tested using paired $\mathrm{t}$ tests.

\section{Results}

The physical characteristics are indicated in Table 1. The significant differences were not found in the values for physical characteristics (BMI, body fat and lean body mass) in BEF and AFT the PW program. The lipid concentrations in each muscle are indicated in Tables 2-4. Significant differences were not found for IMCL concentrations in 
Page 3 of 5

each muscle between BEF and AFT the PW program (Table 2) (NS). A significant reduction was recognized in EMCL concentrations (Table 3) and EMCL/IMCL ratio (Table 4) on TA $(\mathrm{p}<0.05)$ and MG $(\mathrm{p}<0.01)$ between the values before $\mathrm{PW}$ and those after. Blood lipid and lipoprotein profiles are shown in Table 5. Mean HDL-C $(\mathrm{p}<0.01)$ and TC $(\mathrm{p}<0.05)$ concentrations increased after completion of the PW program. A decrease in VLDL-C $(\mathrm{p}<0.05)$ and HDL-C/LDL-C ratio $(\mathrm{p}<0.01)$ was also observed at this point.

\begin{tabular}{|l|l|l|l|l|l|l|}
\hline \multicolumn{2}{|l|}{ M. tibialis anterior } & \multicolumn{2}{l|}{ M. soleus } & \multicolumn{2}{l|}{ M. medial gastrocnemius } \\
\hline (n=6) & Before & After & Before & After & Before & After \\
\hline \multirow{2}{*}{$\begin{array}{l}\text { IMCL } \\
\text { contents }\end{array}$} & 3.57 & 1.8 & 9.69 & 10.9 & 6.34 & 10.5 \\
\cline { 2 - 7 } & \pm 0.8 & \pm 1.4 & \pm 3.7 & \pm 3.8 & \pm 3.5 & \pm 6.4 \\
\hline
\end{tabular}

Table 2: Comparisons of IMCL in each muscle on before and after the $\mathrm{PW}$ program; Values are means $\pm \mathrm{SD}$ expressed as $\mathrm{mmol} / \mathrm{kg}$ wet $\mathrm{wt}$; $\mathrm{n}=6$, TA: Tibialis Anterior Muscle; MG: Medial Gastrocnemius Muscle; SOL: Soleus Muscle; IMCL: Intramyocellular Lipids; PW: Pole-Assisted Walking.

\begin{tabular}{|l|l|l|l|l|l|l|}
\hline \multicolumn{3}{|c|}{ M. tibialis anterior } & \multicolumn{2}{c|}{ M. soleus } & \multicolumn{1}{c|}{ M. medial trocnemius } \\
\hline$(n=6)$ & Before & After & Before & After & Before & After \\
\hline \multirow{2}{*}{$\begin{array}{l}\text { EMCL } \\
\text { contents }\end{array}$} & 10.4 & 6.2 & 14 & 15.9 & 27.3 & 20.5 \\
\cline { 2 - 7 } & \pm 5.5 & $\pm 4.7^{*}$ & \pm 5.8 & \pm 7.4 & \pm 11.0 & $\pm 13.5^{\star *}$ \\
\hline
\end{tabular}

Table 3: Comparisons of EMCL in each muscle on before and after the $\mathrm{PW}$ program, Values are means $\pm \mathrm{SD}$ expressed as $\mathrm{mmol} / \mathrm{kg}$ wet $\mathrm{wt}$; $\mathrm{n}=6,{ }^{*} \mathrm{p}<0.05,{ }^{* *} \mathrm{p}<0.01$ Significantly differences in before and after the PW program; EMCL: Extra myocellular lipids; PW: Pole-use Assisted Walking.

\begin{tabular}{|l|l|l|l|l|l|l|}
\hline \multicolumn{2}{|l|}{ M. tibialis anterior } & \multicolumn{2}{l|}{ M. soleus } & \multicolumn{2}{l|}{ M. medial strocnemius } \\
\hline (n=6) & Before & After & Before & After & Before & After \\
\hline \multirow{2}{*}{$\begin{array}{l}\text { EMCL/IMCL } \\
\text { (unit) }\end{array}$} & 3.15 & 1.8 & 1.54 & 1.43 & 4.65 & 2.13 \\
\cline { 2 - 7 } & \pm 2.1 & $\pm 0.9^{*}$ & \pm 0.8 & \pm 0.3 & \pm 1.4 & $\pm 0.9^{* *}$ \\
\hline
\end{tabular}

Table 4: Comparisons of EMCL/IMCL in each muscle on before and after the PW program, ${ }^{*} \mathrm{p}<0.05,{ }^{* *} \mathrm{p}<0.01$ significantly differences in before and after the PW program. Values are means \pm SD expressed as $\mathrm{mmol} / \mathrm{kg}$ wet wt; $\mathrm{n}=6$, IMCL: Intra myocellular Lipids; EMCL: Extra myocellular Triglycerides; PW: Pole-Assisted Walking.

\begin{tabular}{|l|l|l|}
\hline$(\mathbf{n}=6)$ & Before & After \\
\hline TG $(\mathrm{mg} / \mathrm{dl})$ & $82.5 \pm 0.5$ & $81.0 \pm 8.6$ \\
\hline TC $(\mathrm{mg} / \mathrm{dl})$ & $201.2 \pm 8$ & $214.7 \pm 0.6^{*}$ \\
\hline LDL-C $(\mathrm{mg} / \mathrm{dl})$ & $133.7 \pm 9$ & $124.2 \pm 17.7$ \\
\hline VLDL-C $(\mathrm{mg} / \mathrm{dl})$ & $17.9 \pm 7.0$ & $15.3 \pm 6.2^{*}$ \\
\hline HDL-C (mg/dl) & $49.6 \pm 14.4$ & $75.2 \pm 10.7^{* *}$ \\
\hline LDL/HDL (unit) & $3.24 \pm 2.4$ & $1.69 \pm 0.4^{* *}$ \\
\hline HbA1c (\%) & $5.07 \pm 0.38$ & $5.13 \pm 0.26$ \\
\hline
\end{tabular}

\begin{tabular}{|l|l|l}
\hline glucose $(\mathrm{mg} / \mathrm{dl})$ & $93.3 \pm 4.1$ & $94.0 \pm 8.1$ \\
\hline
\end{tabular}

Table 5: Comparisons of blood lipid, lipoprotein profiles, HbAlcand serum glucose on before and after the PW program, Values are means $\pm \mathrm{SD}^{\star} \mathrm{p}<0.05{ }^{* *} \mathrm{p}<0.001$; TC: Total Cholesterol; TG: Triglyceride; HDL-C: HDL-Cholesterol; LDL-C: LDL-Cholesterol; VLDL-C: VLDLCholesterol; PW: Pole-Assisted Walking.

\section{Discussion}

For many years, it has been reported that aerobic exercise improved maximum oxygen uptake in elderly people $[21,22]$. Therefore, exercise has been recommended for maintenance and improvement of health. The exercise program of this study adopted PW, and evaluated its influence over a 10 weeks period on fat in the skeletal muscle of elderly people using ${ }^{1} \mathrm{H}$-MRS method. The exercise program consisted of three or more sessions per week of PW for 30 min or more per session. Intensity of exercise was fixed at a comfortable walking pace.

Generally, it is known that the energy-supply route from fat during exercise is of three types: plasma free fatty acid (FFA) being released from plasma TG; FFA being released from VLDL-C by the activity of lipoprotein lipase; and FFA being produced within mitochondria through decomposition of IMCL accumulated in muscle cells. Neither subcutaneous fat tissue or viscous triglyceride, or intra-muscle fiber (EMCL) triglyceride directly converts to energy through exercise. EMCL exists as a fat deposit between muscle fibers [2] and does not transform with transient exercises $[23,24]$. It is assumed that, in this study, EMCL slowly and gradually decomposed and was absorbed into the muscle cells where it worked to supplement IMCL with fat energy throughout the period of the program.

The lipid concentrations in the TA, SOL and MG muscles are indicated in Table 2. No significant differences were observed in IMCL concentrations, between BEF and AFT. On the other hand, a remarkable change was recognized in EMCL on TA and MG between $\mathrm{BEF}$ and AFT. Moreover, a significant reduction was recognized in EMCL/IMCL ratio $(\mathrm{p}<0.05)$ on the both muscle at AFT. Postural muscles, such as SOL and TA, are typically involved in continuous force maintenance, and muscle fiber in these muscles is of great functional significance. Especially, TA is the major dorsiflexor of the ankle, with a very homogeneous distribution of activity with in muscle [25]. TA muscle was chosen because of unique properties with respect to IMCL determination by MRS [26]. As a correlation was observed between IMCL and EMCL [27], it is assumed that there is an intimate relationship between the inside and outside of cells in the demand and supply of energy. On the other hand, many studies have reported that IMCL is reduced by $19-33 \%$ immediately after transient exercise $[23,28,29]$. It is evident that IMCL is taken in and consumed in mitochondria directly during exercise. However, IMCL measurement, if carried out even a reasonable time after finishing exercise program, may not show a discernible change, because IMCL is replenished by dietary intake soon after exercise. As IMCL is reported to increase during recovery [30], the values at rest and at recovery cannot be compared in a simple manner. It is probable that IMCL showed no change in this study because measurement was carried out on the day following the completion of the program.

Blood lipid and lipoprotein profiles are shown in Table 3. With regard to blood constituents after PW as compared to before $\mathrm{PW}$, no change was observed in TG or LDL-C, whereas there was a reduction of VLDL-C. From this, it was inferred that in endurance training 
VLDL-C is consumed as the main source of energy [31]. HDL-C increased by $52 \%$ in this study. It is well known that the LDL-C/HDL$\mathrm{C}$ ratio declines, and that HDL-C increases, with aerobic training $[32,33]$. PW should increase aerobic capacity in elderly people. It is assumed that the increase in HDL-C seen in this study was a factor in engendering the increase in TC and the decline in the LDL-C/HDL-C ratio. Therefore, the above suggests that $\mathrm{PW}$ may improve blood lipid and lipoprotein profiles and aerobic work capacity in weak elderly people.

Although few studies have addressed glucose metabolism, Evans et al. [34] reported that aerobics, such as walking, for three sessions per week for nine months improved aerobic ability, increased fat-free mass, and also enhanced insulin sensitivity. One report on diabetic persons [35] showed that control of meal and exercise decreased HbAlc. However, no diabetics were included among the subjects employed in this study. Although blood glucose levels and HbAlc were investigated as indices of the glucose metabolism in this study, no change was observed after PW in either value.

\section{Conclusion}

These results suggest that pole-assisted walking at a comfortable pace may improve lipid metabolism in the elderly nursing home residents. Moreover, it is believed that walking with poles prevents falls in weak elderly people while providing them with a remarkable aerobic benefit.

\section{Disclosure}

The authors report no conflicts of interest in this work.

\section{Acknowledgement}

The authors wish to thank the subjects for their enthusiastic participation in this investigation. We would also like to thank Harada $\mathrm{K}$, Shirase R and Okano G of the Sapporo Medical University, Hokkaido, Japan. This work was supported by JSPS KAKENHI Grant Number 14380003.

\section{References}

1. Fiatarone MA, O'Neill EF, Ryan ND, Clements KM, Solares GR, et al. (1994) Exercise training and nutritional supplementation for physical frailty in very elderly people. N Engl J Med 330: 1769-1775.

2. Bessen DH, Rupp CL, Eckel RH (1995) Trafficking of dietary fat in lean rats. Obesity Res 3:191-203.

3. Madden MC, Winkle BV, Kirk K, Pike MM, Pohst GM, et al. (1993) $1 \mathrm{H}$ NMR spectroscopy can accurately quantitate the lipolysis and oxidation of cardiac triacylglycerols. Biochim Biophys Acta 1169: 176-182.

4. Szczepaniak LS, Babcock EE, Schick F, Dobbins RL, Garg A, et al. (1999) Measurement of intracellular triglyceride stores by ${ }^{1} \mathrm{H}$ spectroscopy: validation in vivo. Am J Physiol Endocrinol Metab 276: E977-E989.

5. Holloszy J, Coyle EF (1984) Adaptation of skeletal muscle to endurance exercise and their metabolic consequences. J Appl Physiol 56: 831-838.

6. Blaak EE, Van Aggel-Leijssen DP, Wagenmakers AJ, Saris WH, Van Baak MA (2000) Impaired oxidation of plasma-derived fatty acids in type 2 diabetic subjects during moderate-intensity exercise. Diabetes 49: 2102-2107.

7. Colberg SR, Simoneau JA, Thaete FL, Kelley DE (1995) Skeletal muscle utilization of free fatty acids in women with visceral obesity. J Clin Invest 95: 1846-1853.
8. Schrauwen P, Van Aggel-Leijssen DPC, Hul G, Wagenmakers AJM, Vidal $\mathrm{H}$, et al. (2002) The effect of a 3 month low-intensity endurance training program on fat oxidation and acetyl-CoA carboxylase-2 expression. Diabetes: 51: 2220-2226.

9. Horowitz JF, Leone TC, Feng W, Kelly DP, S Klein (2000) Effect of endurance training on lipid metabolism in women: A potential role for PPA Ralpha in the metabolic respose to training. Am J Physiol Endocrinol Metab 279: E348-E355.

10. Klein S, Coyle EF, Wolfe RR (1994) Fat metabolism during low-intensity exercise in endurance-trained and untrained men. Am J Physiol Endocrinol Metab 267: E934-E940.

11. Turcotte LP, Richter E A, Kiens B (1992) Increase plasma FFA uptake and oxidation during prolonged exercise in trained vs. untrained humans. Am J Physiol Endocrinol Metab 262: E791-E799.

12. Van Loon LJ, Jeukendrup AE, Saris WH, Wagenmakers AJ (1999) Effect of training status on fuel selection during submaximal exercise with glucose ingestion. J Appl Physiol 87: 1413-1420.

13. Toda Y, Segal N, Toda T, Morimoto T, Ogawa R (2000) Lean body mass and body fat distribution in participants with chronic low back pain. Arch Intern Med 160: 3265-3269.

14. Sato I, Hyakuta M, Hayashi F, Mukai M, Kondo S, Maeda E, Kumagai S (2002) Usefulness of examination of the cholesterol versus triglyceride ratio for lipoprotein fractions in a patient with marked hypertriglyceridemia. Rinsho Byori 50: 987-991.

15. Hattori M, Nakagawa Y, Harada K, Bando M, Okano G (2006) Characteristics of intramyocellular lipid content in skeletal muscles of overweight men and endurance-trained athletes. Jpn J Phys Fitness Sports Med Suppl 55: S43-S48.

16. Nakagawa Y, Hattori M, Harada K, Shirase R, Bando M, et al. (2007) Agerelated changes in intramyocellular lipid in humans by in vivo ${ }^{1} \mathrm{H}-\mathrm{MR}$ spectroscopy. Gerontology 53: 218-223.

17. Nakagawa Y, Hattori (2017) Intramyocellular lipids of muscle type in athletes of different sport disciplines. Open Access J Sports Med 8: 161-166.

18. Yokota T, Kinugawa S, Okita K, Hirabayashi K, Suga T, et al. (2011) Lower aerobic capacity was associated with abnormal intramuscular energetics in patients with metabolic syndrome. Hypertens Res 34: 1029-1034.

19. Hwang JH, PAN JW, Heydari S, Hetherington HP, Stein DT (2001) Regional differences in intramyocellular lipids in humans observed by in vivo ${ }^{1} \mathrm{H}-\mathrm{MR}$ spectroscopic imaging. J Appl Physiol 90: 1267-1274.

20. Kiens B, Essen-Gustavsson B, Christensen NJ, Saltin B (1993) Skeletal muscle substrate utilization during submaximal exercise in man: Effect of endurance training. J Physiol 469: 459-478.

21. Cononie CC, Graves JE, Pollock ML, Phillips MI, Sumners C, et al. (1991) Effect of exercise training on blood pressure in 70-79 years old men and women. Med Sci Sports Exerc 23: 505-511.

22. Wilson TM, Tanaka H (2000) Meta-analysis of the age-associated decline in maximal aerobic capacity in men: Relation to training status. Am J Physiol Heart Circ Physiol 278: H829-834.

23. Rico-Sanz J, Moosavi M, Thomas EL, McCarthy J, Coutts G, et al. (2000) In vivo evalution of the effect of continuous exercise on skeletal muscle triglyceride in trained human. Lipids 35: 1313-1317.

24. White LJ, Robergs RA, Sibbitt Jr WL, Ferguson MA, McCoy S, et al. (2003) Effects of intermittent cycle exercise on intramyocellular lipid use and recovery. Lipids 38: 9-13.

25. Nakagawa Y, Ratkevicius A, Mizuno M, Quistroff B (2005) ATP economy of force maintenance in human tibialis anterior muscle. Med Sci Sports Exer 37: 937-943.

26. Schmitt B, Fluck M, Decombaz J, Kreis R, Boesch C, et al. (2003) Transcriptinal adaptations of lipid metabolism in tibialis anterior muscle of endurance-trained athletes. Physiol Genomics 15: 148-157.

27. Nakagawa Y, Hattori M, Harada K, Bando M, Okano G (2003) ${ }^{1} \mathrm{H}-\mathrm{MRS}$ study on gender differences in intramuscular triglycerides in human skeletal muscle and their relation to body fat and endurance capacity. Jpn J Phys Fitness Sports Med 52: 149-158. 
Citation: Nakagawa Y, Hattori M (2017) Effect of Pole-Assisted Walking on Intramuscular Lipids in Elderly Nursing Home Residents. J Nurs Care

28. Krssak M, Petersen KF, Bergeron R, Price T, Laurent D, et al. (2000) Intramuscular Glycogen and intramuscular lipid utilization during prolonged exercise and recovery in man: $\mathrm{A}^{13} \mathrm{C}$ and ${ }^{1} \mathrm{H}$ nuclear magnetic resonance spectroscopy study. J Clin Endocrin Metab 85: 748-754.

29. Larson-Meyer DE, Newcomper BR, Hunter GR (2002) Influence of endurance running and recovery diet on intramyocellular lipid content in women: A ${ }^{1} \mathrm{H}$ NMR study. Am J Physiol 282: E95-E106.

30. Decombaz J, Schmitt B, Ith M, Decarli B, Diem P, et al. (2001) Post exercise fat intake repletes intramyocellular lipids but no faster in trained than in sedentary subjects. Am J Physiol Regulatory Integrative Comp Physiol 281: R760-R769.

31. Kimber NE, Heigenhauser GJ, Spriet LL, Dyck DJ (2003) Skeletal muscle fat and carbohydrate metabolism during recovery from glycogendepleting exercise in humans. J Physiol 548:919-927.
32. Sunami Y, Motoyama M, Kinoshita F, Mizooka Y, Sueta K, et al. (1999) Effects of low-intensity aerobic training on the high-density lipoprotein cholesterol concentration in healthy elderly subjects. Metabolism 48: 984-988.

33. Verissimo MT, Aragao A, Sousa A, Barbosa B, Ribeiro H, et al. (2002) Effect of physical exercise on lipid metabolism in the elderly. Rev Port Cardiol 21: 1099-112.

34. Evans EM, Van Pelt RE, Binder EF, Williams DB, Ehsani AA, et al. (2001) Effects of HRT and exercise training on insulin action, glucose tolerance and body composition in older women. J Appl Physiol 90: 2033-2040.

35. Boule NG, Haddad E, Kenny GP, Wells GA, Sigal RJ (2001) Effects of exercise on glycemic control and body mass in type 2 diabetes mellitus: A meta-analysis of controlled clinical trials. JAMA 286: 1218-1227. 